\title{
Assessing Diversity of Diurnal Lepidoptera in Habitat Fragments: Testing the Efficiency of Strip Transects
}

\author{
MATTHEW R. WILLIAMS ${ }^{1}$ \\ Centre for Ecosystem Diversity and Dynamics, Department of Environmental Biology, Curtin University,
} PO Box U1987, Perth, Western Australia 6845, Australia

\section{Environ. Entomol. 37(5): 1313-1322 (2008)}

\begin{abstract}
Species richness is the most widely used measure of biodiversity, but the relationship between the observed and true numbers of species present in a study site is not always investigated. A field study at 27 habitat remnants was used to measure the effectiveness of a survey regimen for assessing species richness of butterflies and day-active moths in southwest Western Australia. Observed species richness was compared with known species richness and to statistical estimates of true species richness, and the bootstrap was found to be the best predictor of true richness. A regimen of 10-m-wide walk transects sampled on six occasions at 2-wk intervals during the austral spring (mid-September to mid-December) gave an almost complete inventory of resident species for each site ( $\approx 87 \%$ of the fauna detected), consistent with two previous studies that have assessed sample completeness in temperate areas. The abundance of diurnal lepidoptera showed large temporal variation over the flight season and varied to a lesser extent with time of day and temperature, but not with cloud cover or wind speed. Transect route and sampling frequency were the most important considerations in devising a survey regimen: transects placed off tracks detected both more species and more individuals per unit length. The fraction of the site area sampled was relatively unimportant, and even low sampling fractions of 1-2\% may be adequate if the number and frequency of surveys is sufficient. The design of future surveys would be facilitated if sampling fraction was routinely reported and examined in relation to sample completeness.
\end{abstract}

KEY WORDS butterflies, day-flying moths, estimating species richness, sample completeness, sampling fraction

Estimating species diversity of an area by means of surveys is a fundamental task in biogeography, ecology, and conservation biology. Although the purposes of such surveys are diverse (e.g., biodiversity assessment, comparison of experimental treatments, assessing effects of habitat characteristics, management or disturbance, or population monitoring), designing an effective survey strategy is essential to obtain reliable results and use resources efficiently. Survey regimens to inventory species diversity are increasing, particularly within habitat fragments, as more conservation agencies seek to document baseline data on biodiversity against which to assess temporal change or change in relation to management practice. Species richness is a widely used measure of biodiversity, but the relationship between the observed and true values of species richness is not always studied (Watson 2003, Kery and Plattner 2007). Some species will not be detected even though they are present at a site, a fact that is commonly overlooked (Mackenzie et al. 2003). This imperfect detection produces underestimates of site occupancy, an important index of the current state

\footnotetext{
${ }^{1}$ Corresponding author, e-mail: Matthew.Williams@dec.wa.gov.au.
}

of a population and a crucial factor in defining conservation priority. Even low rates of false negatives (the failure to detect a species which is present) introduces bias that can confound models of the spatial pattern of biodiversity and have a significant and detrimental effect on habitat occupancy models (Rosenzweig 1995, Tyre et al. 2003). If the false negatives are related to site characteristics, systematic errors may be introduced, possibly leading to erroneous conclusions (Verner 1985, Watson 2003). Thus, failure to verify the accuracy of a survey regimen may have a significant and detrimental impact on subsequent conclusions (Tyre et al. 2003, MacKenzie et al. 2003, 2004, MacKenzie 2005).

To overcome this impediment, abundance- or incidence-based data can be used to estimate true species richness by extrapolating species accumulation curves or by nonparametric methods (Colwell and Coddington 1994). These estimates are more accurate than observed species richness but may still be imprecise or biased (Palmer 1990, Chiarucci et al. 2003, Brose and Martinez 2004, Walther and Moore 2005). The methods vary in accuracy depending on factors such as the species abundance distributions (Colwell and Cod- 
dington 1994) and species mobility (Brose and Martinez 2004), and the best performing estimators vary between data sets (Brose et al. 2003). The efficacy of the various estimators has most often been tested with simulated data, because empirical studies rarely record total species richness (Walther and Moore 2005).

The precision and efficiency of the methods used to assess the diversity of butterflies has seldom been examined (Kery and Plattner 2007). The predominant sampling method is the strip transect: a predetermined route through the study site that is traversed at intervals during the flight season (Douwes 1976, Pollard 1977). The transect is divided into sectors, so that is effectively a set of contiguous plots, and all individuals within a defined distance from the observer(s) are identified and tallied. Transect length may be fixed (Cowley et al. 2001a, b; Saarinen 2002a, b; Saarinen and Jantunen 2002, Caldas and Robbins 2003) or variable (Thomas 1983, Panzer 2002, Krauss et al. 2003, Mac Nally and Fleishman 2002). Originally devised to monitor the abundance of butterflies, the method is now used widely to inventory butterflies in remnant habitat. However, the considerations that apply to survey strategies for assessing abundance also apply generally to assessing species richness. To devise a survey regimen, a number of parameters must be defined: transect route, width and length; number, frequency and timing of surveys; and time of day and weather restrictions. The strip transect method is also used widely to inventory other taxa, notably birds (Rosenstock et al. 2002).

The aim of this study was to measure the effectiveness of the strip transect method for assessing species richness of butterflies and day-active moths in southwest Western Australia and to quantify its level of precision. Specifically, three questions were addressed: (1) in obtaining species lists to a prescribed level of accuracy, what is the optimal combination of transect length, number, timing and frequency of surveys?; (2) should transects be conducted using existing tracks and walk paths or be placed randomly?; and (3) what constitutes acceptable weather conditions for conducting surveys?

\section{Materials and Methods}

Strip transects were placed in 27 habitat remnants within the Swan Coastal Plain bioregion (Thackway and Cresswell 1995), southwest Western Australia. This region has a Mediterranean-type climate with a pronounced summer drought and is prone to frequent fires (Hopper and Gioia 2004). Vegetation at the sites was predominantly low open woodland or low open forest dominated by Banksia or Eucalyptus, although some contained wetland and sedgeland vegetation, coastal heathland, or estuarine-fringing vegetation (Beard 1990). Most sites were selected from a comprehensive review of remnant vegetation within the Perth metropolitan region (Western Australian Government 2000); full details of the sites are given by Williams (2008)
The Australian butterfly fauna is well documented (Braby 2000): 56 species occur within the southwest region, of which 10 are introduced, occasional migrants or vagrants. Of the native species, 28 have been recorded within the study area. The majority of these (20 species) are univoltine or predominantly so, with a single annual generation of adults restricted to spring, and only one species has an exclusively autumn-flying generation. The day-active moth fauna is less well studied, and the number of taxa within the study region is unknown. The most notable are the sun-moths (Synemon spp., Castniidae), which are conspicuous day-active moths that are often confused with butterflies. With only 45 Australian species, they are a small group in comparison with butterflies, although 24 of these species are known from the southwest region, almost one half the number of native butterfly species (Edwards 1997a, b). One species has a distribution restricted to the study region: the univoltine, autumn-flying species Synemon gratiosa, which is listed as endangered (Burbidge 2004). However, little is known about the others, many of which are poorly collected (Edwards 1997a). Only moth species that were actively flying during the day were included in the study; others that required flushing to be observed were not recorded. For butterflies, taxonomy follows the standard works of Braby (2000); for day-flying moths, taxonomy follows Common (1990) and Edwards (1997b).

At each site, a fixed-route transect was established to sample variation in vegetation type, structure, and regeneration age since the last fire. Transect length varied with site area, ranging from 190 to $5,100 \mathrm{~m}$, and smaller sites typically had shorter transects but a higher sampling fraction (the fraction of the site area sampled by the strip transect). Full details of the sampling methods are provided by Williams (2008). As a pilot study, one remnant was sampled intensively on $36 \mathrm{~d}$ over a 58 - $\mathrm{d}$ period between late October and mid-December 2001, and in 2002, five remnants were sampled on 7-13 occasions from mid-October to late December and in March 2003. In spring 2003, all of the remnants were sampled at fortnightly intervals on six occasions from mid-September to late December and twice between late February and early April 2004.

In all analyses, species that are vagrants, migrants, or introduced to the region were excluded, a standard approach used by previous studies (Hill 1987, Braby and Edwards 2006). This division is equivalent to the concept of "matrix" and "island" species (Pollard and Yates 1993): matrix (nonresident) species are typically highly dispersive, common, occur in both remnant habitat and intervening areas, and are of little conservation concern; island (resident) species typically have low dispersal rates, are local or uncommon, and are restricted to remaining suitable habitat patches.

To assess the completeness of the species lists for each site, observed resident species richness was compared with known species lists and with estimates of species richness predicted using statistical extrapolation. Because only one butterfly and one moth species 
Table 1. Species richness of resident butterflies and day-active moths in spring at three sites with known species lists compared with estimated richness using statistical extrapolation

\begin{tabular}{|c|c|c|c|c|c|c|c|c|c|}
\hline \multirow{3}{*}{$\begin{array}{c}\text { Known resident } \\
\text { species } \\
\text { Year }\end{array}$} & \multicolumn{3}{|c|}{ Koondoola } & \multicolumn{2}{|c|}{ Warwick } & \multicolumn{2}{|c|}{ Cottonwood } & \multirow{3}{*}{ MSE } & \multirow{3}{*}{ SMSE } \\
\hline & \multicolumn{3}{|c|}{13} & \multicolumn{2}{|c|}{12} & \multicolumn{2}{|c|}{9} & & \\
\hline & 2001 & 2002 & 2003 & 2002 & 2003 & 2002 & 2003 & & \\
\hline Estimator Surveys & 36 & 10 & 6 & 5 & 6 & 4 & 6 & & \\
\hline S obs & 11 & 13 & 12 & 10 & 11 & 8 & 7 & 2.14 & 0.018 \\
\hline $\mathrm{ACE}$ & 11.5 & 17.5 & 12.0 & 11.5 & 11.3 & 8.4 & 7.4 & 3.79 & 0.025 \\
\hline ICE & 11.5 & 14.7 & 12.3 & 13.7 & 11.4 & 10.8 & 8.3 & 1.84 & 0.015 \\
\hline Chao 1 & 11.0 & 16.0 & 12.0 & 10.3 & 11.0 & 8.0 & 7.0 & 3.26 & 0.024 \\
\hline Chao 2 & 11.0 & 14.4 & 12.0 & 12.4 & 11.0 & 8.8 & 8.5 & 1.19 & 0.008 \\
\hline Jack 1 & 12.0 & 15.7 & 12.8 & 13.2 & 11.8 & 10.3 & 7.2 & 2.09 & 0.017 \\
\hline Jack 2 & 12.9 & 17.4 & 12.4 & 15.2 & 10.9 & 11.1 & 8.7 & 5.01 & 0.035 \\
\hline Bootstrap & 11.5 & 14.2 & 12.6 & 11.4 & 11.7 & 9.1 & 8.0 & 0.79 & 0.006 \\
\hline MM Runs & 10.7 & 14.4 & 14.9 & 32.5 & 16.5 & 16.1 & 15.0 & 76.89 & 0.600 \\
\hline MM Means & 10.9 & 14.7 & 14.7 & 13.0 & 15.2 & 10.6 & 11.2 & 4.19 & 0.033 \\
\hline
\end{tabular}

Absolute (MSE = mean square error) and relative (SMSE = scaled MSE) measures of accuracy are give for each method, with smaller values indicating greater precision.

are known to fly exclusively in autumn, and abundances in autumn were very low, only the data from the spring surveys were used in this analysis. To determine the best extrapolation method for these data, the approach suggested by Colwell and Coddington (1994) was used: the predictions of a number of methods were compared with known inventories. Accurate species lists could be determined for three sites, based on the collections of the Western Australian Museum, the Western Australian Department of Environment and Conservation, and the records of amateur collectors. Amateur collectors tend to be biased, in that they are more prone to overlook common, easily detected species, but this bias is useful in detecting rare species. Nine extrapolation methods that have been shown to provide good results were compared: two that use abundance data (ACE, Chao-1) and seven that use site occupancy data (ICE, Chao-2, jack-1, jack-2, bootstrap, MM runs, and MM means). Details of these estimators are given by Colwell and Coddington (1994) and Colwell (2005). Estimates were calculated using the EstimateS software package (Colwell 2005) and compared with known values using both absolute and relative measures of accuracy (the mean square error, MSE = sum of squared errors, and scaled MSE, SMSE = sum of squared relative errors, respectively; Walther and Moore 2005).

At four sites, the off-track surveys were compared with adjacent, paired sectors of equal length extracted from the longer on-track surveys on the 33 sampling occasions when both transect types were conducted. Average counts for each species and for the total number of individuals were compared by two-way analysis of variance (ANOVA) using the SAS statistical package (proc GLM; SAS Institute 2006). Logarithmic transformation $[\log (x+1)]$ was necessary to satisfy the assumptions underlying ANOVA of approximate normality and homoscedasticity of residuals.

The effects of site, sampling period, time of day, weather conditions, and the number of observers on counts and on the number of species detected were analyzed using a general linear model. Each survey was allocated to one of nine sampling periods, corresponding to the half-monthly intervals from mid-September to late December or to the first or second half of March. The time of day at the mid-point of each survey was allocated to 1 of 12 half-hourly intervals. Average temperature during each transect was allocated to 1 of 11 classes $\left(2^{\circ} \mathrm{C}\right.$ intervals above $\left.15^{\circ} \mathrm{C}\right)$, wind speed into five classes (5-km/h intervals), and cloud cover to the nearest okta. Weather data (hourly air temperature, wind speed, and 3-h cloud cover) were obtained from the Bureau of Meteorology Perth metropolitan recording station, located $<20 \mathrm{~km}$ from all of the study sites. Counts were logarithmically transformed and species richness was square-root transformed to satisfy the assumptions underlying the model.

\section{Results}

In total, the survey regimen was comprised of 660 $\mathrm{km}$ of walk transects and sampled 14,605 individuals. I recorded 33 butterfly and 3 day-flying moth species (23 resident and 13 nonresident) with individual site richness varying between 0 and 25 species; only 5 butterfly species known from the region were not detected. Full results of the surveys are detailed in Williams (2008).

Comparison of the alternative methods of predicting resident species richness showed that the bootstrap estimator was the most accurate, having the lowest absolute and relative measures of error (Table 1). Of the other estimators, Chao- 2 was of comparable accuracy to the bootstrap, but all except the bootstrap produced occasional anomalous predictions that were in error by $20 \%$ or more of true richness. Although the bootstrap predictions underestimated true richness on average by 0.4 species, this was not significantly different from zero ( $95 \%$ confidence interval $=-0.4$, 1.2). Repeated sampling at the three sites over $2-3$ yr produced consistent estimates (range, 78-100\%) and averaged $88 \%$ of the known of species richness (Table 2 ). Assuming the total number of resident species 
Table 2. Observed, known, and predicted butterfly and day-active moth fauna using statistical extrapolation at 27 remnant bushland sites on the Swan Coastal Plain, southwest Western Australia

\begin{tabular}{|c|c|c|c|c|c|c|c|}
\hline \multirow[b]{2}{*}{ Site } & \multicolumn{3}{|c|}{ Observed } & \multicolumn{2}{|c|}{ Known } & \multicolumn{2}{|c|}{ Predicted } \\
\hline & $\begin{array}{l}\text { Total } \\
\text { species }\end{array}$ & $\begin{array}{l}\text { Nonresident } \\
\text { species }\end{array}$ & $\begin{array}{c}\text { Resident } \\
\text { species }\end{array}$ & $\begin{array}{c}\text { Resident } \\
\text { species }\end{array}$ & $\begin{array}{l}\text { Resident species } \\
\text { detected }(\%)\end{array}$ & $\begin{array}{l}\text { Resident } \\
\text { species }\end{array}$ & $\begin{array}{c}\text { Resident species } \\
\text { detected }(\%)\end{array}$ \\
\hline Bold Park & 15 & 5 & 9 & & & 9.9 & 91 \\
\hline Cottonwood & 13 & 4 & 9 & 9 & 100 & 9.9 & 91 \\
\hline Cottonwood 2002 & & & 8 & & 89 & & \\
\hline Cottonwood 2003 & & & 7 & & 78 & & \\
\hline Errina Rd & 15 & 4 & 10 & & & 11.0 & 91 \\
\hline Fred Samson & 8 & 3 & 5 & & & 5.8 & 87 \\
\hline Harry Sandon & 7 & 4 & 1 & & & 1.3 & 75 \\
\hline Hillview & 4 & 2 & 2 & & & 2.4 & 85 \\
\hline Kensington & 3 & 3 & 0 & & & - & \\
\hline Kings Park & 11 & 5 & 5 & & & 5.1 & 99 \\
\hline Koondoola & 25 & 11 & 13 & 13 & 100 & 13.1 & 100 \\
\hline Koondoola 2001 & & & 11 & & 85 & & \\
\hline Koondoola 2002 & & & 13 & & 100 & & \\
\hline Koondoola 2003 & & & 12 & & 92 & & \\
\hline Landsdale & 10 & 4 & 6 & & & 6.9 & 86 \\
\hline Marangaroo & 16 & 5 & 10 & & & 11.2 & 90 \\
\hline Mt Henry & 10 & 3 & 6 & & & 6.6 & 92 \\
\hline Point Resolution & 1 & 1 & 0 & & & - & \\
\hline Shenton & 5 & 2 & 2 & & & 2.4 & 85 \\
\hline Shepherds Bush & 9 & 3 & 6 & & & 6.9 & 87 \\
\hline Signal Hill & 4 & 4 & 0 & & & - & \\
\hline Star Swamp & 12 & 4 & 7 & & & 8.1 & 86 \\
\hline Trigg E & 6 & 2 & 3 & & & 3.3 & 90 \\
\hline Trigg N & 13 & 6 & 7 & & & 8.7 & 80 \\
\hline Trigg S & 10 & 5 & 4 & & & 4.5 & 89 \\
\hline Trigg W & 6 & 2 & 4 & & & 4.7 & 84 \\
\hline Wal Hughes & 2 & 2 & 0 & & & - & \\
\hline Warwick & 20 & 7 & 11 & 12 & 92 & 11.2 & 98 \\
\hline Warwick 2002 & & & 10 & & 83 & & \\
\hline Warwick 2003 & & & 11 & & 92 & & \\
\hline Warwick N & 15 & 3 & 10 & & & 11.1 & 90 \\
\hline Warwick SE & 17 & 5 & 11 & & & 11.9 & 92 \\
\hline Warwick SW & 13 & 3 & 9 & & & 10.6 & 85 \\
\hline Wireless Hill & 9 & 4 & 4 & & & 5.0 & 80 \\
\hline Total/average & 36 & 13 & 23 & & 88 & & 87 \\
\hline
\end{tabular}

predicted to occur at the remaining sites is accurate, the sampling regimen detected $87 \%$ of the fauna (range, 75-99\%). The estimated fraction of species detected at each site was positively related to the number of observed species $\left(R^{2}=0.33, P=0.003\right)$ and to $\log$ (site area) $\left(R^{2}=0.32, P=0.03\right)$ and negatively but weakly related to sampling fraction $\left(R^{2}=0.11, P=\right.$ $0.10 ;$ Fig. 1 ). This result is unaffected by the point with high leverage on the right of Fig. 1c. Thus, the estimated proportion of species detected was generally lower in small, species-poor sites that had higher sampling fractions.

Comparison of species richness and counts between transect types showed that off-track routes generally detected both more species and individuals (Table 3 ). Four species were detected only off tracks and one only on tracks, although three of these cases were singletons. Three species showed statistically significant differences in counts between transect types, with more individuals detected off tracks in each case. The overall density of individuals varied substantially between sites, but overall density off tracks was approximately twice that on tracks.

Sampling period and site had significant effects on both counts and the number of species detected, with sampling period having the largest impact (Table 4).
There was a pronounced peak in density of both individuals and species in November and, other than the very low counts in the autumn surveys, counts in late December yielded the fewest individuals (Fig. 2). Mean density of individuals was significantly lower before 1000 hours and after 1430 hours (Fig. 2; mean density between 1000 and 1430 hours $=0.39$ individuals per $100 \mathrm{~m}$ of transect, outside this period mean density $=0.16$ individuals per $100 \mathrm{~m} ; P=0.05$ by post hoc single degreeof-freedom contrast). Temperature, weather conditions, and the number of observers did not significantly affect either counts or the number of detected species. Counts were reasonably consistent between 20 and $32^{\circ} \mathrm{C}$; outside this range, they were more variable.

\section{Discussion}

The sampling regimen used in this study detected $88 \%$ of the known and $87 \%$ of the estimated resident fauna. In contrast to its usually poor accuracy, the bootstrap was the best estimator of total species richness, although performance of estimators is known to vary between data sets (Walther and Moore 2005). Only two previous studies have examined sampling adequacy for butterflies in temperate regions. In Switzerland, the Swiss Biodiversity Monitoring Scheme 

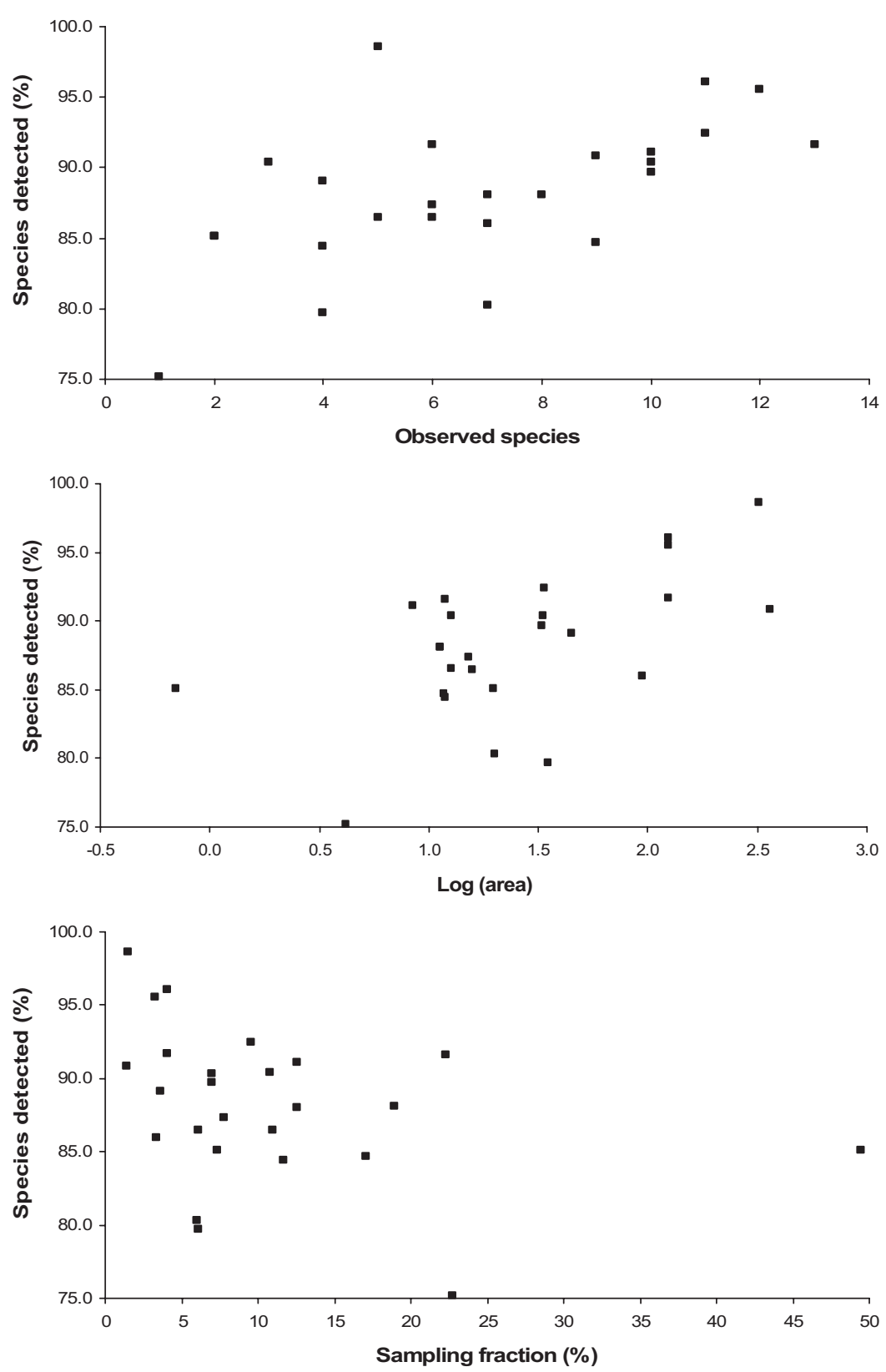

Fig. 1. Proportion of the estimated resident species richness detected in relation to (a) observed species richness, (b) site area, and (c) fraction of the site sampled.

inventoried butterflies with seven surveys conducted over $5 \mathrm{mo}$, using 2.5-km-long, 5-m-wide transects within $1-\mathrm{km}^{2}$ grid cells (i.e., a sampling fraction of $1.25 \%)$. This regimen detected $66-70 \%$ of taxa present (Birrer et al. 2005, Kery and Plattner 2007). In South Australia, Collier et al. (2006) studied three urban remnants using 10-m-wide transects; I calculated the sampling fraction at these sites to be $0.3,1.9$, and $3.4 \%$. The surveys, conducted over two flight seasons, detected $75-82 \%$ of the estimated total fauna in the first year (8-10 surveys at an average 1-mo interval), and
$69-80 \%$ of the fauna in the second year (9 surveys at fortnightly intervals). The site with the smallest sampling fraction had the lowest proportion of the fauna detected each year (69 and 75\%), whereas the other two sites were similar (80 and $80 \%, 82$ and $76 \%$ ). In both of these studies, the figures for actual and expected total species included migratory, vagrant, and introduced species, and it could be expected that the figures for resident species detected were higher. Combining the results of all three studies suggests that, at sampling fractions above $\approx 1 \%$, monthly surveys 
Table 3. Number of individuals observed per $100 \mathrm{~m}$ (means and SEs) for on- and off-track transect surveys of diurnal lepidoptera at four sites on the Swan Coastal Plain, southwest Western Australia

\begin{tabular}{|c|c|c|c|c|c|c|c|c|c|}
\hline & \multirow{4}{*}{$\begin{array}{l}\text { Survey type } \\
\text { Number of surveys } \\
\text { Survey length }(\mathrm{m})\end{array}$} & \multicolumn{2}{|c|}{ Cottonwood } & \multicolumn{2}{|c|}{ Koondoola } & \multicolumn{2}{|c|}{ Landsdale } & \multicolumn{2}{|c|}{ Warwick } \\
\hline & & Off & On & Off & On & Off & On & Off & $\mathrm{On}$ \\
\hline & & 3 & 3 & 18 & 18 & 8 & 8 & 4 & 4 \\
\hline & & 717 & 710 & 929 & 949 & 273 & 313 & 760 & 758 \\
\hline \multirow[t]{3}{*}{ Trapezites sciron } & Count & 0 & 0 & 2 & 0 & 0 & 1 & 0 & 0 \\
\hline & Mean & 0.00 & 0.00 & 0.01 & 0.00 & 0.00 & 0.04 & 0.00 & 0.00 \\
\hline & $\mathrm{SE}$ & 0.00 & 0.00 & 0.01 & 0.00 & 0.00 & 0.04 & 0.00 & 0.00 \\
\hline \multirow{3}{*}{$\begin{array}{l}\text { Motasingha trimaculata } \\
\text { and } M \text {. dirphia }{ }^{a}\end{array}$} & Count & 7 & 0 & 6 & 0 & 0 & 0 & 0 & 0 \\
\hline & Mean & 0.33 & 0.00 & 0.04 & 0.00 & 0.00 & 0.00 & 0.00 & 0.00 \\
\hline & $\mathrm{SE}$ & 0.33 & 0.00 & 0.02 & 0.00 & 0.00 & 0.00 & 0.00 & 0.00 \\
\hline \multirow[t]{3}{*}{ Mesodina cyanophracta ${ }^{a}$} & Count & 8 & 1 & 111 & 30 & 2 & 0 & 2 & 0 \\
\hline & Mean & 0.37 & 0.05 & 0.66 & 0.18 & 0.09 & 0.00 & 0.07 & 0.00 \\
\hline & $\mathrm{SE}$ & 0.23 & 0.05 & 0.13 & 0.04 & 0.09 & 0.00 & 0.04 & 0.00 \\
\hline \multirow[t]{3}{*}{ Taractrocera papyria } & Count & 0 & 0 & 0 & 0 & 0 & 0 & 1 & 0 \\
\hline & Mean & 0.00 & 0.00 & 0.00 & 0.00 & 0.00 & 0.00 & 0.03 & 0.00 \\
\hline & $\mathrm{SE}$ & 0.00 & 0.00 & 0.00 & 0.00 & 0.00 & 0.00 & 0.03 & 0.00 \\
\hline \multirow[t]{3}{*}{ Geitoneura klugii } & Count & 38 & 10 & 33 & 45 & 0 & 0 & 10 & 3 \\
\hline & Mean & 1.77 & 0.47 & 0.20 & 0.26 & 0.00 & 0.00 & 0.33 & 0.10 \\
\hline & SE & 1.09 & 0.17 & 0.05 & 0.05 & 0.00 & 0.00 & 0.17 & 0.06 \\
\hline \multirow[t]{3}{*}{ Heteronympha merope } & Count & 1 & 0 & 4 & 0 & 0 & 0 & 0 & 0 \\
\hline & Mean & 0.05 & 0.00 & 0.02 & 0.00 & 0.00 & 0.00 & 0.00 & 0.00 \\
\hline & SE & 0.05 & 0.00 & 0.02 & 0.00 & 0.00 & 0.00 & 0.00 & 0.00 \\
\hline \multirow[t]{3}{*}{ Hypochrysops halyaetus } & Count & 1 & 1 & 61 & 70 & 0 & 0 & 30 & 21 \\
\hline & Mean & 0.05 & 0.05 & 0.36 & 0.41 & 0.00 & 0.00 & 0.99 & 0.69 \\
\hline & $\mathrm{SE}$ & 0.05 & 0.05 & 0.11 & 0.15 & 0.00 & 0.00 & 0.70 & 0.40 \\
\hline \multirow[t]{3}{*}{ Nacaduba biocellata } & Count & 0 & 0 & 0 & 0 & 0 & 0 & 1 & 0 \\
\hline & Mean & 0.00 & 0.00 & 0.00 & 0.00 & 0.00 & 0.00 & 0.03 & 0.00 \\
\hline & SE & 0.00 & 0.00 & 0.00 & 0.00 & 0.00 & 0.00 & 0.03 & 0.00 \\
\hline \multirow[t]{3}{*}{ Neolucia agricola } & Count & 1 & 4 & 55 & 77 & 0 & 1 & 0 & 0 \\
\hline & Mean & 0.05 & 0.19 & 0.33 & 0.45 & 0.00 & 0.04 & 0.00 & 0.00 \\
\hline & $\mathrm{SE}$ & 0.05 & 0.19 & 0.10 & 0.10 & 0.00 & 0.04 & 0.00 & 0.00 \\
\hline \multirow[t]{3}{*}{ Zizina labrudus } & Count & 0 & 0 & 0 & 1 & 0 & 0 & 0 & 0 \\
\hline & Mean & 0.00 & 0.00 & 0.00 & 0.01 & 0.00 & 0.00 & 0.00 & 0.00 \\
\hline & $\mathrm{SE}$ & 0.00 & 0.00 & 0.00 & 0.01 & 0.00 & 0.00 & 0.00 & 0.00 \\
\hline \multirow[t]{3}{*}{ Synemon sp. aff. sophia ${ }^{a}$} & Count & 5 & 4 & 308 & 166 & 1 & 1 & 7 & 2 \\
\hline & Mean & 0.23 & 0.19 & 1.84 & 0.97 & 0.05 & 0.04 & 0.23 & 0.07 \\
\hline & SE & 0.17 & 0.19 & 0.31 & 0.19 & 0.05 & 0.04 & 0.11 & 0.07 \\
\hline \multirow[t]{3}{*}{ Synemon gratiosa } & Count & 0 & 0 & 1 & 1 & 0 & 0 & 0 & 0 \\
\hline & Mean & 0.00 & 0.00 & 0.01 & 0.01 & 0.00 & 0.00 & 0.00 & 0.00 \\
\hline & $\mathrm{SE}$ & 0.00 & 0.00 & 0.01 & 0.01 & 0.00 & 0.00 & 0.00 & 0.00 \\
\hline \multirow[t]{3}{*}{ Pollanisus cupreus } & Count & 0 & 0 & 0 & 1 & 4 & 6 & 0 & 0 \\
\hline & Mean & 0.00 & 0.00 & 0.00 & 0.01 & 0.18 & 0.24 & 0.00 & 0.00 \\
\hline & SE & 0.00 & 0.00 & 0.00 & 0.01 & 0.18 & 0.24 & 0.00 & 0.00 \\
\hline \multirow[t]{3}{*}{ Total $^{a}$} & Count & 70 & 33 & 1122 & 688 & 18 & 21 & 55 & 28 \\
\hline & Mean & 3.25 & 1.55 & 6.71 & 4.03 & 0.82 & 0.83 & 1.81 & 0.92 \\
\hline & SE & 1.80 & 0.57 & 0.84 & 0.44 & 0.30 & 0.29 & 0.90 & 0.46 \\
\hline
\end{tabular}

${ }^{a}$ Significant difference between on- and off-track surveys by two-way ANOVA, $\left.P<0.05\right)$.

detected $65-80 \%$ of the fauna and fortnightly surveys increased this to $75-90 \%$.

The lack of any positive relationship between the fraction of resident species detected and sampling fraction seems counter-intuitive. It might be expected that increased sampling fractions should detect a greater proportion of the species present, although this may not necessarily follow for mobile species such

Table 4. ANOVA of counts $[\log (x+1)$ transformed $]$ and species richness (square root-transformed) of diurnal lepidoptera in 290 surveys of 27 sites in southwest Western Australia

\begin{tabular}{|c|c|c|c|c|c|c|c|}
\hline \multirow[b]{2}{*}{ Source } & \multirow[b]{2}{*}{$\mathrm{df}$} & \multicolumn{3}{|c|}{ Count } & \multicolumn{3}{|c|}{ Species richness } \\
\hline & & $\begin{array}{l}\text { Mean } \\
\text { square }\end{array}$ & $F$ & $P$ & $\begin{array}{l}\text { Mean } \\
\text { square }\end{array}$ & $F$ & $P$ \\
\hline Site & 26 & 4.68 & 7.19 & $<0.0001$ & 0.113 & 7.73 & $<0.0001$ \\
\hline Sampling period & 8 & 15.62 & 23.98 & $<0.0001$ & 0.177 & 12.05 & $<0.0001$ \\
\hline Time of day & 11 & 1.44 & 2.21 & 0.01 & 0.024 & 1.65 & 0.09 \\
\hline No. of observers & 2 & 0.60 & 0.92 & 0.40 & 0.006 & 0.40 & 0.67 \\
\hline Cloud cover & 7 & 0.28 & 0.44 & 0.88 & 0.011 & 0.74 & 0.64 \\
\hline Temperature & 10 & 0.73 & 1.13 & 0.34 & 0.009 & 0.62 & 0.79 \\
\hline Wind speed & 4 & 0.79 & 1.21 & 0.31 & 0.032 & 2.18 & 0.07 \\
\hline Residual & 221 & 0.65 & & & 0.015 & & \\
\hline
\end{tabular}



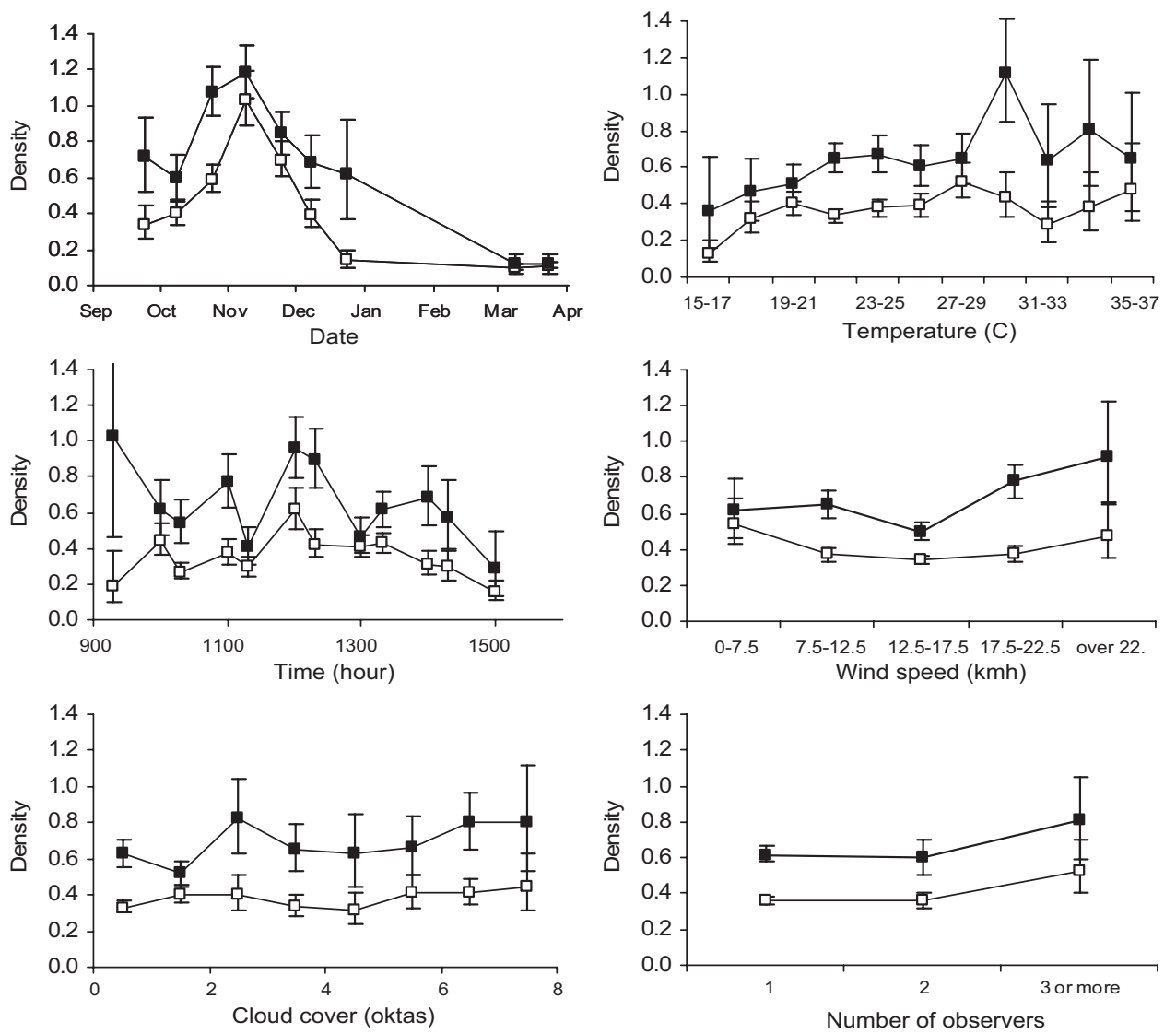

Fig. 2. Density of diurnal lepidoptera in transect surveys in south-west Western Australia: mean number of species detected per $\mathrm{km}$ of transect $\pm \mathrm{SE}$ (closed symbols); and mean number of individual insects detected per $100 \mathrm{~m}$ of transect \pm SE (open symbols), in relation to (a) time of year (fortnightly intervals in spring and autumn); (b) time of day (half-hourly intervals); (c) cloud cover (oktas); (d) temperature $\left(2^{\circ} \mathrm{C}\right.$ intervals); (e) wind speed ( $5 \mathrm{~km} / \mathrm{h}$ intervals); and (f) number of observers.

as butterflies that have varying levels of detectability and seasonal flight periods (Brose and Martinez 2004, Kery and Plattner, 2007). The results show that sampling frequency and sampling fraction need to be considered together: once sampling fraction is adequate, effort is better allocated to more frequent surveys. In a comparable study of birds, Watson (2003) showed that increased site visits were more productive than extended sampling times, and this is likely to apply equally to butterflies.

Watson (2003) also discussed the issues relating to fixed- and variable-area sampling in habitat patches: if sampling area within each patch is a fixed size quadrat (as is the usual practice in bird surveys, and a common practice in surveys of butterflies), the quadrat becomes the focus, not the patch. This prevents hypotheses being framed in terms of the patch characteristics, such as area or number of habitats, because the quadrats sample a fixed area and a fixed number of habitats that may not be reflective of the patch area or the number of habitats within the patch. However, it is almost invariably the patch that is of interest, not the quadrat. Some practical problems also arise if the sam- ple area is fixed. In this study, the smallest patch was $0.7 \mathrm{ha}$, and if fixed-area sampling was used, this would limit transect length to $700 \mathrm{~m}$ in all other patches: for the largest site, this would result in a sampling fraction of $0.2 \%$. In sampling isolated remnants, fixing transect length across all sites may result in over- or undersampling of small and large remnants, respectively. If species richness increases with area, which is usually the case, this would result in substantial bias.

Using only existing tracks introduced bias in which species were detected and affected estimates of their relative abundance. Numerous studies have shown that many butterfly species favor open areas, such as tracks or early successional habitats (New 1991, Thomas and Hanski 1997, Dover and Rowlingson 2005), open habitats, habitat edges, and artificial environments such as roads, cleared corridors under powerlines, and field margins (Munguira and Thomas 1992, Yahner 1996, 1999, Bramble et al. 1999, Wahlberg et al. 2002, Saarinen 2002a, Saarinen et al. 2005, Forrester et al. 2005). In contrast, this study found no evidence of any species that favored tracks, and more 
species and individuals were detected in undisturbed vegetation.

Three interrelated factors, time of day, weather conditions, and time of year, are known to affect the activity of diurnal lepidoptera (Pollard 1977), and this was also found to be the case in this study. Time of year had a large impact on counts but, within broad limits, weather, time of day, and the number of observers had minor or negligible effects. This accords with the findings of Pollard and Yates (1993) in Monk's Wood, England, who showed that the week of recording had the greatest effect on counts and in comparison the effects of time of day, weather, and number of observers were relatively small. In England, northern Europe, and the northern United States, threshold temperatures (usually $13-17^{\circ} \mathrm{C}$; Pollard 1977, Bergman et al. 2004, Clausen et al. 2001, Kraus et al. 2003, Yahner 1999, 2001, Keller and Yahner 2002, Swengel 1996, 1998a, 1998b, Swengel and Swengel 2001) are considerably lower than elsewhere (typically $18-25^{\circ} \mathrm{C}$; Caldas and Robbins 2003, Rudolph and Ely 2000). The results of this study agree with these findings, and conducting surveys between 19 and $33^{\circ} \mathrm{C}$ produced consistent counts.

The observed number of species may be a misleading indicator of true species richness unless sampling adequacy is confirmed. This study found that even low sampling fractions were adequate to detect the majority of species and that the number and hence frequency of surveys is more likely to be a critical factor in maximizing species detection. A practical approach to compiling species lists is to set sampling effort above some minimum fraction of the site area and to sample all of the habitats present, including those resulting from disturbance. The sampling effort should be greatest in more species-diverse areas; in this study, the relatively small fauna was adequately inventoried with six site visits and sampling fractions of $1.3 \%$ or greater. However, such a low sampling fraction may be inadequate in more species-rich areas, in undisturbed sites, less open habitats, or sites with greater spatial variation in habitat types. The necessary sampling fraction to detect particular species also varies with the density of individuals, their behavior, and temporally (MacKenzie 2005). To attain a defined level of sampling adequacy, proportional sampling or the use of resultsbased stopping rules (Soberon and Llorente 1993, Colwell and Coddington 1994, Watson 2003) may be a more valuable method of increasing the efficiency of surveys. Comparisons between studies and the design of future surveys of remnant habitat would be facilitated if sampling fraction was routinely reported and examined in relation to sample completeness.

\section{Acknowledgments}

I thank P. Robertson, K. Botteon, L. Seaman, H. Rind, J. Pryde, G. Pattorini, D. Ruddock, N. Emery, J. Ciampini, K. Clarke, A. Williams, P. Darby, J. Darby, L. Turk, S. Cullen, I. Abbott, R. McElroy, J. Pezzarini, M. Braby, and M. Bremmer for field assistance. T. Edwards and G. Tarmann kindly provided information on the specific identity of the day-flying moths. M. Braby, I. Abbott, and B. Lamont provided valuable comments on the manuscript.

\section{References Cited}

Beard, J. S. 1990. Plant life of Western Australia. Kangaroo Press, Kenthurst, Australia.

Bergman, K.-O., J. Askling, O. Ekberg, H. Ignell, H. Wahlman, and P. Milberg. 2004. Landscape effects on butterfly assemblages in an agricultural region. Ecography 27: 619-628.

Birrer, S., M. Plattner, and P. Ramseier. 2005. Evaluation of the Swiss transect method. In Programme and Abstracts, Butterfly Conservation 5th International Symposium: Lepidoptera as Indicators of Biodiversity Conservation, 8-10 April, Southampton University.

Braby, M. F. 2000. The butterflies of Australia: their identification, biology and distribution. CSIRO Publishing, Collingwood, Australia.

Braby, M. F., and T. D. Edwards. 2006. The butterfly fauna of the Griffith district, a fragmented semi-arid landscape in inland southern New South Wales. Pacific Cons. Biol. 12: $130-154$.

Bramble, W. C., R. H. Yahner, and W. R. Byrnes. 1999. Effect of herbicide maintenance of an electric transmission line right-of-way on butterfly populations. J. Arbor. 25: $302-310$.

Brose, U., and N. D. Martinez. 2004. Estimating species richness of species with variable mobility. Oikos 105: 292-300.

Brose, U., N. D. Martinez, and R. J. Williams. 2003. Estimating species richness: sensitivity to sample coverage and insensitivity to spatial patterns. Ecology 84: 23642377.

Burbidge, A. A. 2004. Threatened animals of Western Australia. Department of Conservation and Land Management, Kensington, Western Australia, Australia.

Caldas, A., and R. K. Robbins. 2003. Modified Pollard transects for assessing tropical butterfly abundance and diversity. Biol. Conserv. 110: 211-219.

Chiarucci, A., N. J. Enright, G.L.W. Perry, B. P. Miller, and B. B. Lamont. 2003. Performance of nonparametric species richness estimators in a high diversity plant community. Div. Distr. 9: 283-295.

Clausen, H. D., H. B. Holbeck, and J. Reddersen. 2001. Factors influencing abundance of butterflies and burnet moths in the uncultivated habitats of an organic farm in Denmark. Biol. Conserv. 98: 167-178.

Collier, N., D. A. Mackay, K. Benkendorff, A. D. Austin, and S. M. Carthew. 2006. Butterfly communities in South Australian urban reserves: Estimating abundance and diversity using the Pollard walk. Austral. Ecol. 31: 282-290.

Colwell, R. K. 2005. EstimateS: Statistical estimation of species richness and shared species from samples. Version 7.5. User's Guide and application. (http:// purl.oclc.org/ estimates).

Colwell, R. K., and J. A. Coddington. 1994. Estimating terrestrial biodiversity through extrapolation. Phil. Trans. Roy. Soc. B 345: 101-118.

Common, I.F.B. 1990. Moths of Australia. Melbourne University Press, Carlton, Australia.

Cowley, M. R., C. D. Thomas, D. B. Roy, R. J. Wilson, J. L. Leon-Cortes, D. Gutierrez, C. R. Bulman, R. M. Quinn, D. Moss, and K. J. Gaston. 2001a. Density-distribution relationships in British butterflies. I. The effect of mobility and spatial scale. J. Anim. Ecol. 70: 410-425.

Cowley, M. R., C. D. Thomas, R. J. Wilson, J. L. Leon-Cortes, D. Gutierrez, and C. R. Bulman. 2001b. Density-distri- 
bution relationships in British butterflies. II. An assessment of mechanisms. J. Anim. Ecol. 70: 426-441.

Douwes, P. 1976. An area census method for estimating butterfly population numbers. J. Res. Lepidop. 15: 146152.

Dover, J. W., and B. Rowlingson. 2005. The western jewel butterfly (Hypochrysops halyaetus): factors affecting adult butterfly distribution within native Banksia bushland in an urban setting. Biol. Conserv. 122: 599-609.

Edwards, E. D. 1997a. Moths in the sun. ANIC News 10, April 1997.

Edwards, E. D. 1997b. Castniidae and the republic. ANIC News 11, October 1997.

Forrester, J. A., D. J. Leopold, and S. D. Hafner. 2005. Maintaining critical habitat in a heavily managed landscape: effects of power line corridor management on karner blue butterfly (Lycaeides melissa samuelis) habitat. Restoration Ecol. 13: 488-498.

Hill, C. J. 1987. Butterflies, pp. 122-125. In C. P. Catterall and C. J. Wallace (eds.), An island in suburbia: the natural and social history of Toohey forest. Institute of Applied Environmental Research, Griffith University, Brisbane, Queensland, Australia.

Hopper, S. D., and P. Gioia. 2004. The southwest Australian floristic region: Evolution and conservation of a global hot spot of biodiversity. Annu. Rev. Ecol. Evol. Syst. 35: 623650.

Keller, G. S., and R. H. Yahner. 2002. Butterfly communities in two Pennsylvania National Parks. Northeast. Nat. 9: 235-242.

Kery, M., and M. Plattner. 2007. Species richness estimation and determinants of species detectability in butterfly monitoring programmes. Ecol. Entomol. 32: 53-61.

Krauss, J., I. Steffan-Dewenter, and T. Tscharntke. 2003. Local species immigration, extinction, and turnover of butterflies in relation to habitat area and habitat isolation. Oecolgia (Berl.) 137: 591-602

MacKenzie, D. L. 2005. Was it there? Dealing with imperfect detection for species presence/absence data. Aust. N.Z.J. Stat. 47: 65-74.

MacKenzie, D. L., L. L. Bailey, and J. D. Nichols. 2004 Investigating species co-occurrence patterns when species are detected imperfectly. J. Anim. Ecol. 73: 546-555.

MacKenzie, D. L., J. D. Nichols, J. E. Hines, M. G. Knutson, and A. D. Franklin. 2003. Estimating site occupancy, colonization and local extinction probabilities when a species is not detected with certainty. Ecology 84: 2200 2207.

MacNally, R., and E. Fleishman. 2002. Using "indicator" species to model species richness: model development and predictions. Ecol. Applic. 12: 79-92.

Munguira, M. L., and J. A. Thomas. 1992. Use of road verges by butterfly and burnet populations, and the effect of roads on adult dispersal and mortality. J. Appl. Ecol. 29: 316-329.

New, T. R. 1991. Butterfly conservation. Oxford University Press, Melbourne, Australia.

Palmer, M. W. 1990. The estimation of species richness by extrapolation. Ecology 71: 1195-1198.

Panzer, R. 2002. Compatibility of prescribed burning with the conservation of insects in small, isolated prairie reserves. Conserv. Biol. 16: 1296-1307.

Pollard, E. 1977. A method for assessing changes in the abundance of butterflies. Biol. Conserv. 12: 115-134.

Pollard, E., and T. J. Yates. 1993. Monitoring butterflies for ecology and conservation. Chapman \& Hall, London, United Kingdom.
Rosenstock, S. S., D. R. Anderson, K. M. Giesen, T. Leukering, and M. F. Carter. 2002. Landbird counting techniques: current practices and an alternative. Auk 119: 46-53.

Rosenzweig, M. L. 1995. Species diversity in space and time Press Syndicate of the University of Cambridge, Cambridge, United Kingdom.

Rudolph, D. C., and C. A. Ely. 2000. The influence of fire on lepidopteran abundance and community structure in forested habitats of eastern Texas. Texas J. Sci. 52: 127-138

Saarinen, K. 2002a. A comparison of butterfly communities along field margins under traditional and intensive management in SE Finland. Agric. Ecosyst. Environ. 90: $59-65$.

Saarinen, K. 2002b. Butterfly communities in relation to changes in the management of agricultural environments. $\mathrm{PhD}$ dissertation, University of Joensuu, Joensuu, Finland.

Saarinen, K., and J. Jantunen. 2002. A comparison of the butterfly fauna of agricultural habitats under different management history in Finnish and Russian Karelia. Ann. Zool. Fenn. 39: 173-181.

Saarinen, K., A. Valtonen, J. Jantunen, and S. Saarino. 2005. Butterflies and diurnal moths along road verges: does road type affect diversity and abundance? Biol. Conserv. 123 403-412.

SAS Institute. 2006. SAS 9.1.3 procedures guide, 2nd ed. SAS Institute, Cary, NC.

Soberón, J., and J. Llorente. 1993. The use of species accumulation functions for the prediction of species richness. Conserv. Biol. 7: 480-488.

Swengel, A. B. 1996. Effects of fire and hay management on abundance of prairie butterflies. Biol. Conserv. 76: 73-85.

Swengel, A. B. 1998a. Comparisons of butterfly richness and abundance measures in prairie and barrens. Biodivers. Conserv. 7: 1639-1659.

Swengel, A. B. 1998b. Effects of management on butterfly abundance in tallgrass prairie and pine barrens. Biol Conserv. 83: 77-89.

Swengel, A. B., and S. R. Swengel. 2001. Effects of prairie and barrens management on butterfly faunal composition. Biodivers. Conserv. 10: 1757-1785.

Thackway, R., and I. D. Cresswell. 1995. An interim biogeographic regionalisation for Australia: a framework for setting priorities in the National Reserves System Cooperative Program. Reserve Systems Unit, Australian Nature Conservation Agency, Canberra, Australia.

Thomas, C. D., and I. Hanski. 1997. Butterfly metapopulations, pp. 359-386. In I. Hanski and M. Gilpin (eds.) Metapopulation biology: ecology, genetics and evolution. Academic, San Diego, CA.

Thomas, J. A. 1983. A quick method for estimating butterfly numbers during surveys. Biol. Conserv. 27: 195-211.

Tyre, A. J., B. Tenhumberg, S. A. Field, D. Niejalke, K. Parris, and H. P. Possingham. 2003. Improving precision and reducing bias in biological surveys: estimating false-negative error rates. Ecol. Applic. 13: 1790-1801.

Verner, J. 1985. Assessment of counting techniques, pp 247-301. In R.F. Johnstone (ed.), Current ornithology, vol. 2. Plenum, New York

Wahlberg, N., T. Klemetti, and I. Hanski. 2002. Dynamic populations in a dynamic landscape: the metapopulation structure of the marsh fritillary butterfly. Ecography 25 224-232.

Walther, B. A., and J. L. Moore. 2005. The concepts of bias, precision and accuracy, and their use in testing the performance of species richness estimators, with a literature review of estimator performance. Ecography 28: 815-829. 
Watson, D. M. 2003. The 'standardized search': an improved way to conduct bird surveys. Austral. Ecol. 28: 515-525.

Western Australian Government. 2000. Bush forever. Western Australian Planning Commission, Perth, Australia.

Williams, M. R. 2008. Butterflies and day-active moths in a fragmented urban landscape, south-western Australia: patterns of species richness. Pac. Conserv. Biol. (in press).
Yahner, R. H. 1996. Butterfly and skipper communities in a managed forested landscape. Northeast Wildl. 53: 1-9.

Yahner, R. H. 1999. Edge use by butterfly communities in agricultural landscapes. Northeast Wildl. 54: 13-24.

Yahner, R. H. 2001. Butterfly communities in residential landscapes of central Pennsylvania. Northeast. Nat. 8: 113-118.

Received 17 July 2006; accepted 8 May 2008. 